\title{
MyD88-dependent Toll-like receptor 4 signal pathway in intervertebral disc degeneration
}

\author{
CHUQIANG QIN, BO ZHANG, LIANG ZHANG, ZHI ZHANG, LE WANG, LONG TANG, \\ SHUANGQING LI, YIXI YANG, FUGUO YANG, PING ZHANG and BO YANG

\begin{abstract}
Department of Orthopedic Surgery, The Third Affiliated Hospital, Guangzhou Medical University,
\end{abstract} \\ Guangzhou, Guangdong 510150, P.R. China
}

Received February 16, 2015; Accepted April 1, 2016

DOI: $10.3892 /$ etm.2016.3425

\begin{abstract}
Lower back pain (LBP) is a common and remitting problem. One of the primary causes of LBP is thought to be degeneration of the intervertebral disc (IVD). The aim of the present study was to investigate the role of the myeloid differentiation primary-response protein 88 (MyD88)-dependent Toll-like receptor 4 (TLR4) signal pathway in the mechanism of IVD degeneration. IVD nucleus pulposus cells isolated and cultured from the lumbar vertebrae of Wistar rats were stimulated by various doses of lipopolysaccharide (LPS; $0.1,1$, 10 and $100 \mu \mathrm{g} / \mathrm{ml}$ ) to simulate IVD degeneration. Cells were rinsed and cultured in serum-free Dulbecco's modified Eagle's medium/F12. Reverse transcription-quantitative polymerase chain reaction was used to determine the levels of TLR4, MyD88, tumor necrosis factor $\alpha(\mathrm{TNF} \alpha)$, and interleukin-1 $\beta$ (IL-1 $\beta$ ) mRNA expression after 1, 3, 6, 9 and $12 \mathrm{~h}$ of incubation. Additionally, western blot and enzyme-linked immunosorbent assay analyses were used to determine the levels of TLR4, MyD88, TNF $\alpha$, and IL-1 $\beta$ protein expression after 24, 48 and $72 \mathrm{~h}$ of incubation. The levels of TLR4, MyD88, TNF $\alpha$ and IL-1 $\beta$ mRNA all increased in the cells stimulated by $10 \mu \mathrm{g} / \mathrm{ml}$ LPS at 3, 6 and $9 \mathrm{~h}$ (all $\mathrm{P}<0.001)$. Furthermore, the levels of TLR4, MyD88, TNF $\alpha$ and IL-1 $\beta$ protein all increased at 24, 48 and $72 \mathrm{~h}$ (all $\mathrm{P}<0.001)$. Additionally, the mRNA and protein levels of TLR4, MyD88, TNF $\alpha$ and IL-1 $\beta$ increased significantly in the cells stimulated by 1,10 and $100 \mu \mathrm{g} / \mathrm{ml}$ LPS compared with the control group, and reached a peak in the $10 \mu \mathrm{g} / \mathrm{ml}$ LPS group (all $\mathrm{P}<0.001$ ). These results suggest that the MyD88-dependent TLR4 signal pathway is a target pathway in IVD degeneration. This pathway is time phase- and
\end{abstract}

Correspondence to: Dr Bo Yang, Department of Orthopedic Surgery, The Third Affiliated Hospital, Guangzhou Medical University, 63 Duobao Road, Guangzhou, Guangdong 510150, P.R. China

E-mail: yangbo141226@163.com

Key words: intervertebral disc degeneration, Toll-like receptors, myeloid differentiation factor 88 , signaling pathway dose-dependent, and when activated can lead to the release of inflammatory factors that participate in IVD degeneration.

\section{Introduction}

Lower back pain (LBP) is a common and remitting problem that cannot be cured but is relieved by current treatments. Multiple studies have demonstrated that $80 \%$ of adults will have at least one episode of back pain during adulthood $(1,2)$. One of the main causes of LBP is thought to be degeneration of the intervertebral disc (IVD) (3). However, current treatments for IVD degeneration and LBP are aimed at relieving symptoms; they are not curative and offer little hope of restoring the IVD to its original function (4). To date, there is no approved conservative therapy to prevent or inhibit IVD degeneration. Therefore, elucidating the mechanisms of IVD degeneration will be necessary for the development of agents to prevent and treat IVD degeneration.

The IVD is a composite tissue, composed of the nucleus pulposus (NP), annulus fibrosis, and cartilaginous end plate. Human IVD degeneration is characterized by changes in architecture and biochemical composition, which alter the disc's ability to bear weight (5). Studies characterizing the extracellular matrix (ECM) and the inflammatory environment of IVD tissue isolated from surgical patients found that degeneration was associated with a loss of proteoglycan (PG) content, an increase in degenerative fibrillation, decreased water content and upregulation of degradative enzymes (6-10). Via an upregulation of molecules such as proinflammatory cytokines and catabolic growth factors, homeostasis of the ECM shifts toward a degenerative, catabolic state with subsequent breakdown of ECM components, including the collagen fibrils surrounding and restraining large, hydrated aggregates of PG, principally aggrecan (11-14). Elevated levels of molecular mediators of inflammation have been described in pathological disc tissue, and have been shown to increase in correlation with the grade of degeneration $(15,16)$. Similar results have been observed for interleukin-1 $\beta$ (IL-1 $\beta$ ) and tumor necrosis factor $\alpha(\mathrm{TNF} \alpha)$, both of which have established roles in regulating nitric oxide (NO) and prostaglandin production, metalloproteinase expression, and apoptosis, all of which are changes that may contribute to the progressive pathology of the IVD (17). Therefore, it is crucial to identify and inhibit 
the key points of the signal pathway responsible for producing proinflammatory cytokines and matrix metalloproteases for the prevention and treatment of IVD degeneration.

The mammalian Toll-like receptors (TLRs), germline-encoded receptors expressed by cells of the innate immune system, are stimulated by structural motifs referred to as pathogen-associated molecular patterns (PAMPs), which are characteristically expressed by bacteria, viruses and fungi $(18,19)$. Notably, TLR interactions trigger the expression of proinflammatory cytokines, as well as the functional maturation of antigen presenting cells of the innate immune system $(19,20)$. TLR4 signals the presence of lipopolysaccharide (LPS) on the cell membrane of gram-negative bacteria and activates an inflammatory response (21). When the majority of TLRs are stimulated, they interact with an adapter protein referred to as myeloid differentiation primary response gene 88 (MyD88), which couples the TLR to downstream signaling kinases, eventually culminating in the activation (by translocation from the cytoplasm to the nucleus) of the transcription factor nuclear factor $\kappa \mathrm{B}(\mathrm{NF}-\kappa \mathrm{B})(22)$. However, MyD88-independent signaling pathways for TLR3 and TLR4 are also known to exist (23). Therefore, TLR4 is able to affect signal transduction in two different ways, either through MyD88 or a TIR domain-containing adapter that induces interferon-beta (TRIF), while TLR3 can signal only through TRIF (24). Although the MyD88-dependent and -independent pathways utilize distinct adapter proteins, both signaling pathways involve the activation and nuclear translocation of $\mathrm{NF}-\mathrm{kB}$, leading to the expression of numerous proinflammatory cytokines. To date, it has been confirmed that the TLR4 gene is expressed in IVD NP cells, and that it plays an important role in the molecular mechanism of IVD degeneration (6). However, the signal transduction pathway that activates the TLR4 in NP cells in IVD degeneration remains unknown, as does the MyD88-dependent or -independent nature of this signal transduction pathway.

The aims of the current study were to determine whether the TLR4 signal pathway in IVD degeneration was MyD88-dependent or -independent, as well as to assess the consequences associated with activation of TLR4 in IVD NP cells. Achievement of these aims may provide direct evidence in support of the hypothesis that the MyD88-dependent TLR4 signal pathway is the target pathway underlying IVD degeneration, as well as providing a theoretical basis for researching the molecular mechanisms underlying IVD degeneration.

\section{Materials and methods}

Isolation and culture of IVD NP cells. Animal experiments were approved by the ethics review board of Guangzhou Medical University (Guangzhou, China) and were performed in accordance with the guidelines on animal use of Guangzhou Medical University. NP cells were isolated from 4-week-old female Wistar rat (weight, 200 g; Laboratory Animal Center, Sun Yat-sen University) lumbar discs using methods reported by Hiyama et al (25). Briefly, the rats were euthanized by injection with an overdose of pentobarbital sodium $(100 \mathrm{mg} / \mathrm{kg}$; Nembutal; Amresco LLC, Cleveland, OH, USA). The spinal column was then removed under aseptic conditions, and the lumbar IVDs were separated under microscopy. The obtained
NP tissue was allowed to digest in a mixture of $0.01 \%$ trypsin (Sigma-Aldrich, St. Louis, MO, USA) at $37^{\circ} \mathrm{C}$ for $15 \mathrm{~min}$. The isolated cells $\left(1 \times 10^{8} \mathrm{~L}^{-1}\right)$ were maintained in Dulbecco's modified Eagle's medium/Nutrient Mixture F-12 (DMEM/F12, 1:1) and $10 \%$ fetal bovine serum supplemented with $100 \mathrm{U} / \mathrm{ml}$ penicillin and $100 \mu \mathrm{g} / \mathrm{ml}$ streptomycin (Gibco; Thermo Fisher Scientific, Inc., Waltham, MA, USA) at $37^{\circ} \mathrm{C}$ in a humidified atmosphere of $5 \% \mathrm{CO}_{2}$. When confluent, the NP cells were harvested and subcultured in $10-\mathrm{cm}$ dishes.

Morphologicalobservation. For the observation of morphology, 6-well culture plates with an additional coverglass in each well were used. The primary or P1 NP chondrocytes that adhered to the coverglasses were used for observation of morphological changes under an inverted phase contrast microscope (IX51; Olympus Corporation, Tokyo, Japan). For hematoxylin and eosin (HE) staining, the coverglasses were washed with phosphate-buffered saline (PBS) prior to fixation in $4 \%$ paraformaldehyde for $30 \mathrm{~min}$, followed by consecutive staining in HE. For Oil Red O staining (Sigma-Aldrich), the coverglasses were washed with PBS and fixed as for HE staining, stained with Oil Red O for $30 \mathrm{~min}$, and counterstained with hematoxylin for another $5 \mathrm{~min}$. For toluidine blue staining, the coverglasses were washed and fixed as for the HE staining, and were immersed for $2 \mathrm{~h}$ in a $1 \%$ toluidine blue solution (KeyGen Biotech Co., Ltd., Nanjing, China) prior to rinsing in $95 \%$ ethanol. For immunohistochemistry staining of collagen II, the endogenous peroxidase was blocked by $3 \% \mathrm{H}_{2} \mathrm{O}_{2}$ in methanol, and then the coverglasses were incubated for $30 \mathrm{~min}$ with anti-human type II collagen antibody (ab34712; Abcam, Cambridge, MA, USA) at a 1:50 dilution. A secondary antibody linked with avidin-biotin-peroxidase (SV0002; Abcam) and 3,3'-diaminobenzidine substrate solutions was used to visualize the immunoreactivity, followed by counterstaining in hematoxylin. Negative control was processed without the anti-rat type II collagen antibody $(26,27)$.

Co-culture of NP cells and LPS. A 6-well co-cultured system was used. LPS was suspended in sterile $\mathrm{dH}_{2} \mathrm{O}$ by sonication, diluted in serum-free media, and re-sonicated immediately prior to use. Cells were rinsed and cultured in serum-free $\mathrm{DMEM} / \mathrm{F} 12$ (control) $\pm \operatorname{LPS}(10 \mu \mathrm{g} / \mathrm{ml})$ for $1,3,6,9$ or $12 \mathrm{~h}$ ( $\mathrm{n}=3-6$ wells per time phase point) prior to use of the reverse transcription-quantitative polymerase chain reaction (RT-qPCR) to determine mRNA (TLR4, MyD88, TNF $\alpha$ and IL-1 $\beta$ ) expression levels, and ensure a best time phase point. In addition, cells were rinsed and cultured in serum-free DMEM/F12 (control) \pm LPS $(10 \mu \mathrm{g} / \mathrm{ml})$ for 24,48 and $72 \mathrm{~h}$ ( $n=3-6$ wells per time phase point), prior to western blot and enzyme-linked immunosorbent assay (ELISA) analyses to determine protein (TLR4, MyD88, TNF $\alpha$ and IL-1 $\beta$ ) expression levels, and ensure a best time phase point. In additional experiments, cells were rinsed and cultured in serum-free DMEM/F12 (control) \pm LPS $(0.1,1,10$ and $100 \mu \mathrm{g} / \mathrm{ml}, \mathrm{n}=3-6$ wells per dose) for different lengths of time (as determined by the results of the qPCR experiment), prior to use of $\mathrm{qPCR}$ to determine the mRNA (TLR4, MyD88, TNF $\alpha$ and IL-1 $\beta$ ) expression levels, and ensure a best dose of LPS. In other experiments, cells were rinsed and cultured in serum-free DMEM/F12 (control) \pm LPS $(0.1,1,10$ and $100 \mu \mathrm{g} / \mathrm{ml}, \mathrm{n}=3-6$ 
Table I. Primers for reverse transcription-quantitative polymerase chain reaction.

\begin{tabular}{lll}
\hline Target & \multicolumn{1}{c}{ Forward primer $\left(5^{\prime}-3^{\prime}\right)$} & \multicolumn{1}{c}{ Reverse primer $\left(5^{\prime}-3^{\prime}\right)$} \\
\hline GAPDH & ATGGGAAGCTGGTCATCAAC & GTGGTTCACACCCATCACAA \\
TLR4 & GAGGACTGGGTGAGAAACGA & AGATACACCAACGGCTCTGG \\
MyD88 & GAGATCCGCGAGTTTGAGAC & CTGTTCTGCTGGTTGCGTA \\
TNF $\alpha$ & CATCTGCTGGTACCACCAGTT & TGAGCACAGAAAGCATGATC \\
$\mathrm{IL}-1 \beta$ & GGGTTCCATGGAGAAGTCAAC & CACCTCTCAAGCAGAGCACAG
\end{tabular}

GAPDH, glyceraldehyde 3-phosphate dehydrogenase; TLR4, Toll-like receptor 4; MyD88, myeloid differentiation primary response gene 88; $\mathrm{TNF} \alpha$, tumor necrosis factor $\alpha$; IL- $1 \beta$, interleukin- $1 \beta$.

wells per dose) for different lengths of time (determined by the results of the western blot and ELISA analyses), prior to the use of western blot and ELISA analyses to determine the protein (TLR4, MyD88, TNF $\alpha$ and IL-1 $\beta$ ) expression levels, and ensure a best dose of LPS.

$R T$ - $q P C R$. Total RNA was isolated from cell cultures at various time phase points using RNAiso Plus reagent (Takara Bio, Inc., Tokyo, Japan), prior to elution from the column, RNA was treated with RNase-free DNase I to remove genomic DNA. Absorbances at 260 and $280 \mathrm{~nm}$ were measured for RNA quantification and quality control. All RNA samples exhibited high quality RNA and were subsequently reverse transcribed to cDNA using the PrimeScript ${ }^{\mathrm{TM}}$ RT reagent kit (Perfect Real Time) according to the manufacturer's instructions (Takara Bio, Inc.). Subsequently, qPCR was conducted to determine the levels of mRNA expression using an ABI Prism 7000 sequence detection system (Applied Biosystems; Thermo Fisher Scientific, Inc., Foster City, CA, USA) in triplicate in 96-well plates in a final volume of $20 \mu \mathrm{l}$ under standard conditions. qPCR was conducted on cDNA samples using the SYBR Green method with SYBR ${ }^{\circledR}$ Premix Ex Taq ${ }^{\mathrm{TM}}$ (Tli RNaseH Plus; Takara Bio, Inc.). Reaction mixes contained $10 \mu \mathrm{l} 2 \mathrm{X}$ SYBR Green mastermix, $1 \mu \mathrm{l}(6 \mu \mathrm{M})$ forward primer, $1 \mu \mathrm{l}(6 \mu \mathrm{M})$ reverse primer, $6 \mu \mathrm{l}$ water and $2 \mu \mathrm{l}(5 \mathrm{ng} / \mu \mathrm{l}) \mathrm{cDNA}$. qPCR was performed as follows: Initial denaturation at $95^{\circ} \mathrm{C}$ for $30 \mathrm{sec}$ for activation of AmpliTaq Cold DNA polymerase (Applied Biosystems; Thermo Fisher Scientific, Inc.), followed by 40 cycles of denaturation at $95^{\circ} \mathrm{C}$ for $5 \mathrm{sec}$, annealing at $60^{\circ} \mathrm{C}$ for $30 \mathrm{sec}$, and extension at $95^{\circ} \mathrm{C}$ for $15 \mathrm{sec}$. Forward and reverse primer sequences are listed in Table I and were synthesized by Takara Bio, Inc. To normalize each sample, a control gene (GAPDH) was used, and the arbitrary intensity threshold of amplification was computed. The $2^{-\Delta \Delta C q}$ method was used to calculate the relative expression of each target gene, as described previously (28).

Western blot analysis. Following treatment, NP cells were immediately placed on ice and washed with cold PBS. Proteins were prepared using the CellLytic NuCLEAR extraction kit (Sigma-Aldrich). Protein quantification was performed using a microplate bicinchoninic acid protein assay kit (Pierce Biotechnology, Thermo Fisher Scientific, Inc., Rockford, IL, USA). All wash buffers and the final resuspension buffer included a $1 \mathrm{X}$ protease inhibitor cocktail
(Pierce Biotechnology), $\mathrm{NaF}(5 \mathrm{mM})$ and $\mathrm{Na}_{3} \mathrm{VO}_{4}(200 \mathrm{mM})$. Nuclear or total cell proteins $(50 \mu \mathrm{g})$ were separated by $10 \%$ sodium dodecyl sulfate polyacrylamide gel electrophoresis and were subsequently electroblotted onto nitrocellulose membranes (Bio-Rad Laboratories, Inc., Hercules, CA, USA). Membranes were blocked with $5 \%$ bovine serum albumin (BSA) in Tris-buffered saline with Tween 20 (TBST: $50 \mathrm{mM}$ Tris, $\mathrm{pH} 7.6,150 \mathrm{mM} \mathrm{NaCl}, 0.1 \%$ Tween 20) and were incubated overnight at $4^{\circ} \mathrm{C}$ in $5 \%$ BSA in TBST with an anti- $\beta$-catenin antibody $(1: 1,000 ; 9582$; Cell Signaling Technology, Inc., Danvers, MA, USA) for $1 \mathrm{~h}$, followed by washing three times with TBS and incubation with a peroxidase-conjugated goat anti-rabbit secondary antibody (1:5,000; 111-035-003; Jackson Immunoresearch, Baltimore, MD, USA) for $2 \mathrm{~h}$ at room temperature. Immunolabeling was detected using enhanced chemiluminescence reagents (Amersham Biosciences; GE Healthcare, Little Chalfont, UK.

ELISA. The concentrations of TNF $\alpha$ and IL-1 $\beta$ in the NP cells were assayed using an ELISA kit (Invitrogen; Thermo Fisher Scientific, Inc., Carlsbad, CA, USA) according to the manufacturer's instructions.

Statistical analysis. Experiments were repeated three times in biological replicates to obtain mean values. Data are presented as the mean \pm standard deviation. Differences among groups were assessed using a one-way analysis of variance. Least significant difference t-tests were used when a single control group was compared with all other groups. Statistical significance $(\mathrm{P}<0.001)$ as compared to control group is denoted with an asterisk $\left(^{*}\right)$. All statistical analyses were conducted using SPSS 13.0 software (SPSS, Inc., Chicago, IL, USA).

\section{Results}

Characterization of IVDNP cells. The third passage of NP cells appeared round or multi-angular with activity. HE staining appeared homogeneous with blue nuclei and pink cytoplasm; no cells size increases were observed. No inhomogeneous or poor light refraction in the cytoplasm was detected (Fig. 1A). Oil Red O staining (Fig. 1B), toluidine blue staining (Fig. 1C) and type II collagen immunohistochemistry staining (Fig. 1D) were all positive and maintained a good cell phenotype. These results indicated that the third passage of NP cells were active 


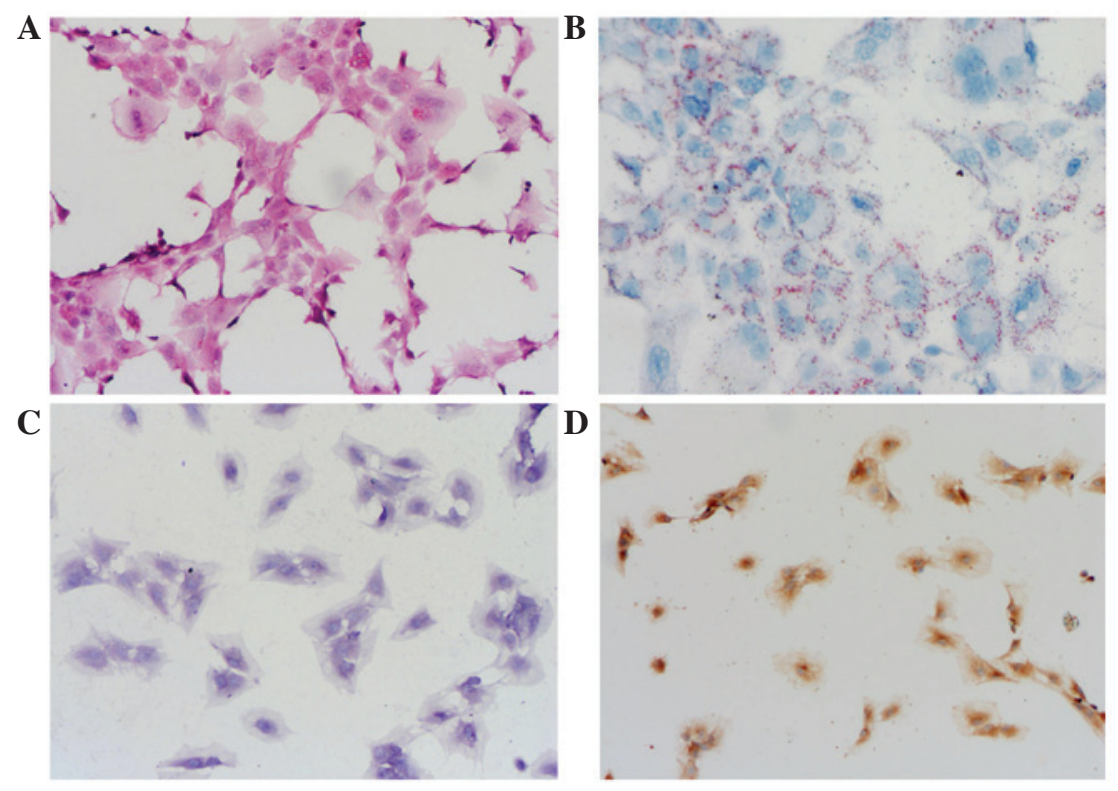

Figure 1. Morphological changes of intervertebral disc nucleus pulposus cells (magnification, x400). (A) Hematoxylin and eosin staining, (B) Oil Red O staining, (C) toluidine blue staining, and (D) type II collagen immunohistochemistry staining.

A
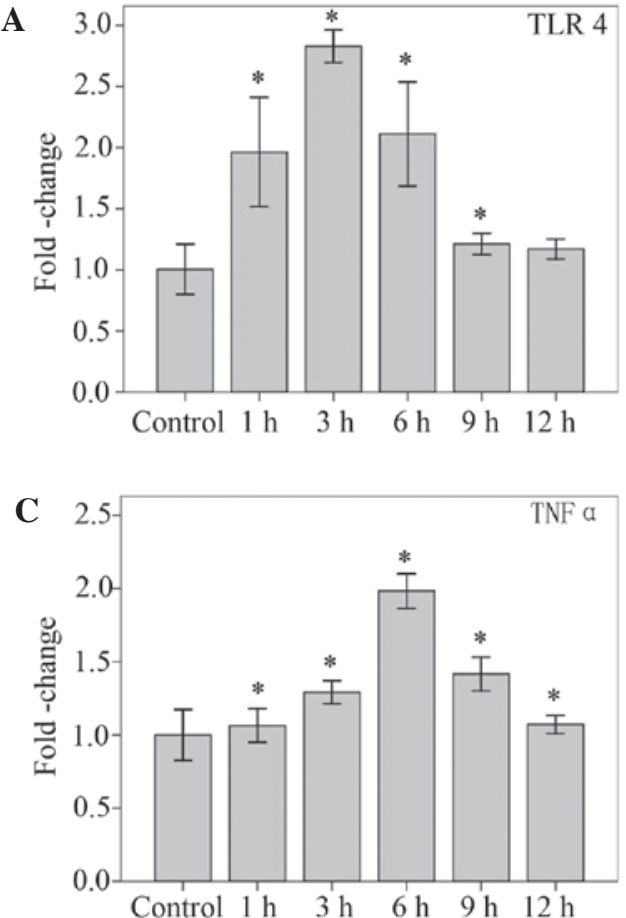
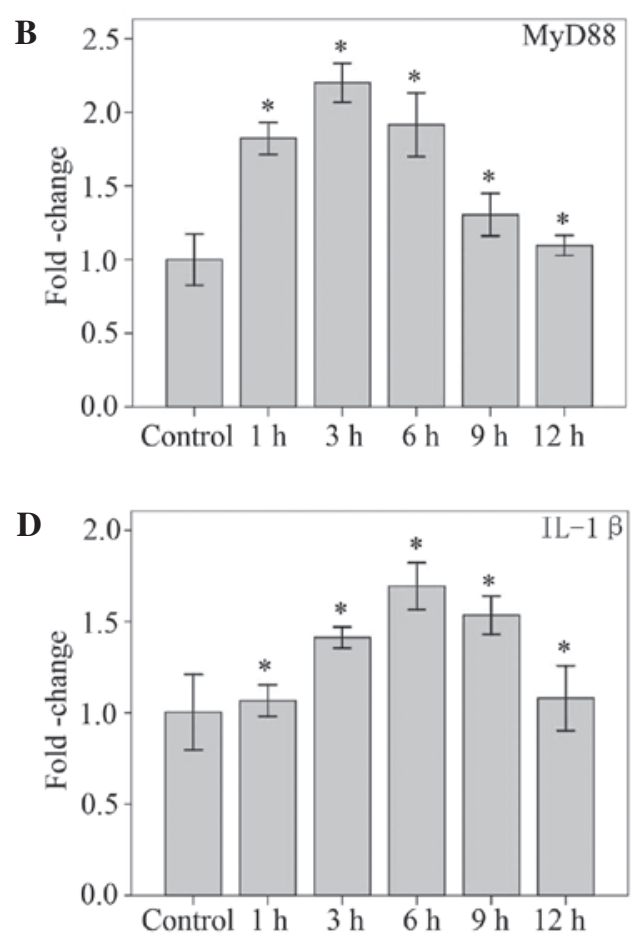

Figure 2. Quantitative analysis of mRNA expression levels in lipopolysaccharide (10 $\mu \mathrm{g} / \mathrm{ml})$-stimulated groups at different time points $(1,3,6,9$ and $12 \mathrm{~h})$ by qPCR. (A) TLR4; (B) MyD88; (C) TNF $\alpha$ and (D) IL-1 3 . Glyceraldehyde 3-phosphate dehydrogenase was used as a control gene. Data are presented as the mean \pm standard deviation from three independent experiments. ${ }^{*} \mathrm{P}<0.001$ vs. control. TLR4, Toll-like receptor 4; MyD88, myeloid differentiation primary response gene 88 ; TNF $\alpha$, tumor necrosis factor $\alpha$; IL-1 $\beta$, interleukin-1 $\beta$.

and homogeneous, thus were fit for researching the molecular mechanism of IVD degeneration.

Time phase-dependent association between LPS and the TLR4 signal pathway (TLR4, MyD88, TNF $\alpha$ and IL-1 $\beta$ ). Using qPCR, mRNA levels for TLR4, MyD88, and the proinflammatory cytokines TNF $\alpha$ and IL-1 $\beta$ were detected in NP cells stimulated with $10 \mu \mathrm{g} / \mathrm{ml}$ LPS. LPS $(10 \mu \mathrm{g} / \mathrm{ml})$ significantly increased the mRNA levels of TLR4 at $1,3,6$ and $9 \mathrm{~h}(\mathrm{P}<0.001$, $\mathrm{P}<0.001, \mathrm{P}<0.001$ and $\mathrm{P}=0.040$, respectively), and MyD88 at 1 , $3,6,9$ and $12 \mathrm{~h}$ (all $\mathrm{P}<0.001)$. The mRNA levels of TNF $\alpha$ and IL-1 $\beta$ increased significantly at $1,3,6,9$ and $12 \mathrm{~h}$ (all $\mathrm{P}<0.001$ ). The peak TLR4, MyD88, TNF $\alpha$ and IL-1 $\beta$ responses were observed at 3, 3, 6 and 6 h, respectively (Fig. 2).

Western blot analysis was used to detect the TLR4 and MyD88 protein levels. Compared with unstimulated control 

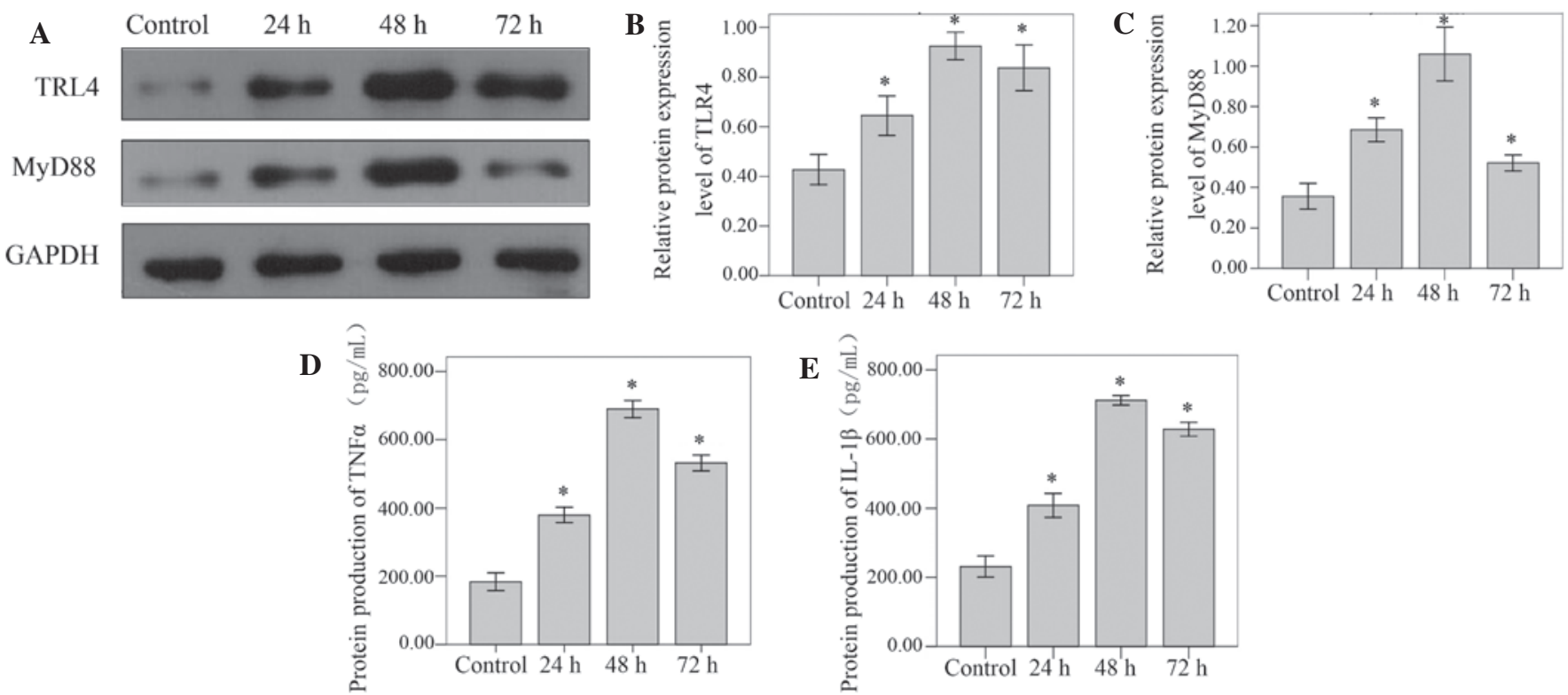

Figure 3. Quantitative analysis of protein expression levels in lipopolysaccharide-stimulated groups at different time points (24, 48 and $72 \mathrm{~h}$ ). (A-C) Western blot analysis of TLR4 and MyD88; enzyme-linked immunosorbent assay analysis of (D) TNF $\alpha$ and (E) IL-1 3 . Glyceraldehyde 3-phosphate dehydrogenase was used as a control gene. Data are presented as the mean \pm standard deviation from three independent experiments. "P $<0.001$ vs. control. TLR4, Toll-like receptor 4; MyD88, myeloid differentiation primary response gene 88; TNF $\alpha$, tumor necrosis factor $\alpha$; IL-1 $\beta$, interleukin-1 $\beta$.
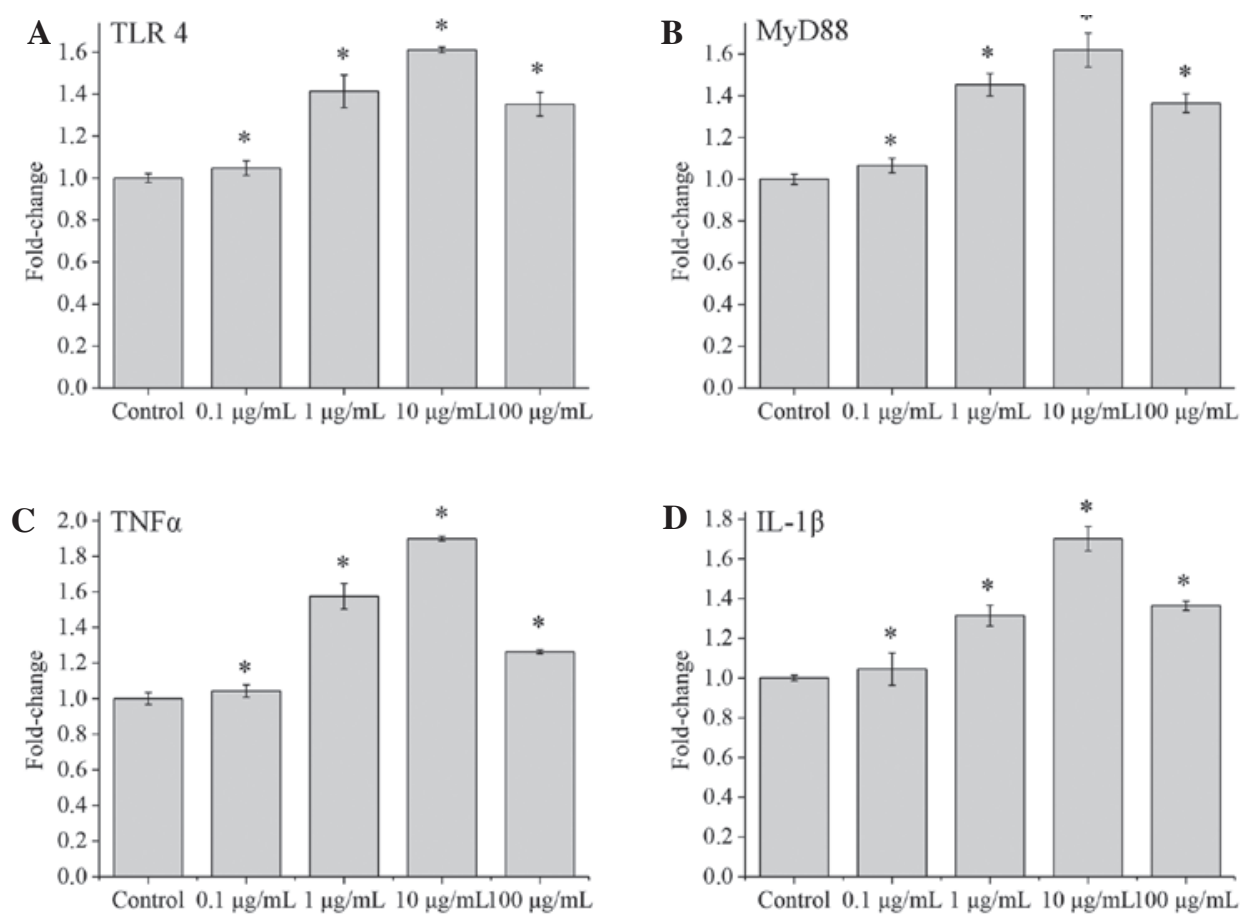

Figure 4. Quantitative analysis of mRNA expression levels in cells stimulated by various concentrations of lipopolysaccharide $(0.1,1,10 \mathrm{and} 100 \mu \mathrm{g} / \mathrm{ml})$ by qPCR. (A) TLR4 and (B) MyD88 were detected after $3 \mathrm{~h}$; (C) TNF $\alpha$ and (D) IL-1 $\beta$ were detected after $6 \mathrm{~h}$. Glyceraldehyde 3-phosphate dehydrogenase was used as a control gene. Data are presented as the mean \pm standard deviation from three independent experiments. "P<0.001 vs. control. TLR4, Toll-like receptor 4; MyD88, myeloid differentiation primary response gene $88 ; \mathrm{TNF} \alpha$, tumor necrosis factor $\alpha$; IL-1 $\beta$, interleukin-1 $\beta$.

cells, the TLR4 and MyD88 protein levels increased significantly at 24,48 and $72 \mathrm{~h}$ (all $\mathrm{P}<0.001)$. Peak protein expression levels were observed at the $48 \mathrm{~h}$ time point for TLR4 and MyD88. (Fig. 3A-C).

The levels of TNF $\alpha$ and IL-1 $\beta$ protein were confirmed via ELISA analysis of the cell supernatants. TNF $\alpha$ and IL-1 $\beta$ protein levels standardized against GAPDH increased significantly at 24,48 and $72 \mathrm{~h}$ in the NP cells stimulated by $10 \mu \mathrm{g} / \mathrm{ml}$ LPS (all $\mathrm{P}<0.001$ ). Levels of both proteins reached a peak at the $48 \mathrm{~h}$ time point (Fig. 3D and E).

Dose-dependent association between LPS and the TLR4 signal pathway (TLR4, MyD88, TNF $\alpha$ and $I L-1 \beta)$. The NP cells stimulated by $0.1,1,10$ and $100 \mu \mathrm{g} / \mathrm{ml}$ LPS were assessed 

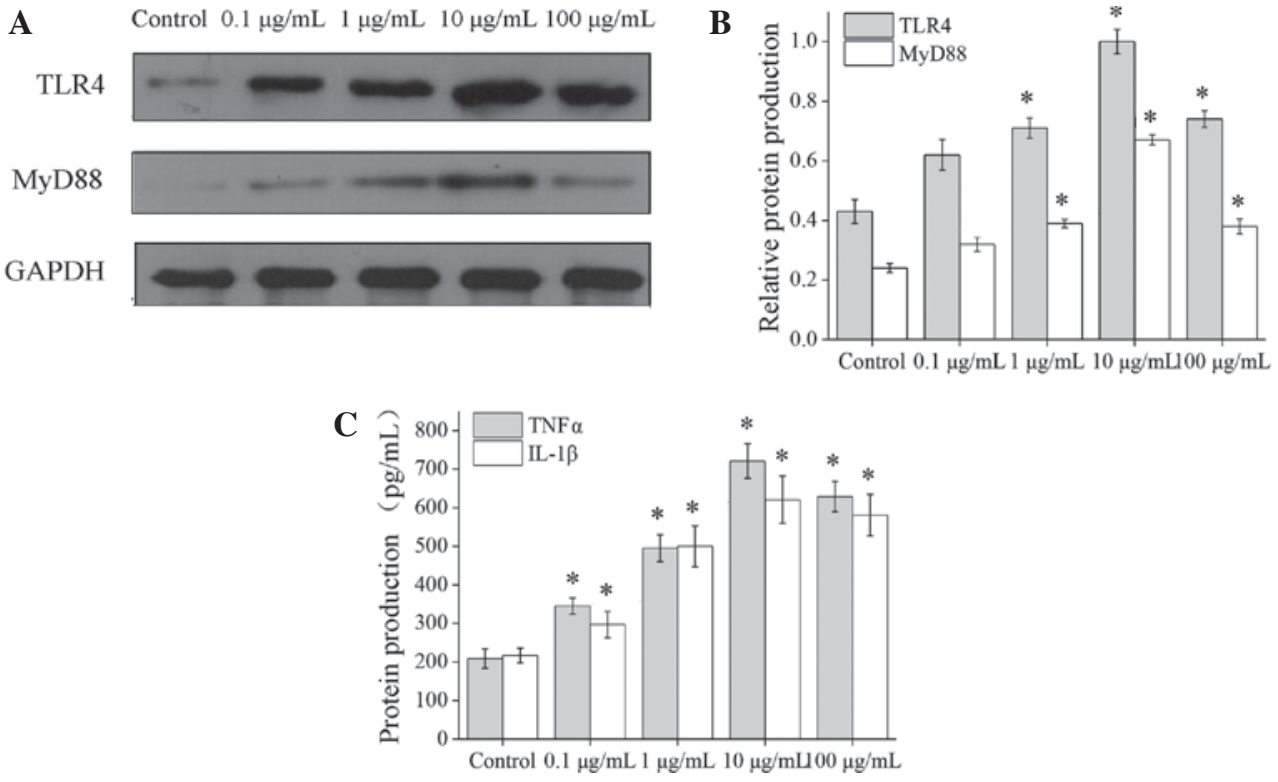

Figure 5. Quantitative analysis of protein expression levels in lipopolysaccharide-stimulated groups $(0.1,1,10$ and $100 \mu \mathrm{g} / \mathrm{ml})$. Western blot analysis of (A) TLR4 and (B) MyD88; (C) enzyme-linked immunosorbent assay analysis of TNF $\alpha$ and IL-1 $\beta$. Glyceraldehyde 3-phosphate dehydrogenase was used as a control gene. Data are presented as the mean \pm standard deviation from three independent experiments. "P $<0.001$ vs. control. TLR4, Toll-like receptor 4; MyD88, myeloid differentiation primary response gene 88; TNF $\alpha$, tumor necrosis factor $\alpha$; IL-1 $\beta$, interleukin-1 $\beta$.

using qPCR. The mRNA levels of TLR4 and MyD88 were detected by qPCR after $3 \mathrm{~h}$, and the mRNA levels of TNFa and IL-1 $\beta$ were detected after $6 \mathrm{~h}$. The results indicated that the mRNA levels of TLR4, MyD88, TNF $\alpha$ and IL-1s increased significantly in the cells stimulated by $0.1,1,10$ and $100 \mu \mathrm{g} / \mathrm{ml}$ LPS as compared to a control group, and reached a peak in the $10 \mu \mathrm{g} / \mathrm{ml}$ LPS group (all P<0.001; Fig. 4).

Using western blot and ELISA analyses, TLR4, MyD88, TNF $\alpha$ and IL-1 $\beta$ proteins were detected in NP cells stimulated with LPS $(0.1,1,10$ and $100 \mu \mathrm{g} / \mathrm{ml})$ for $48 \mathrm{~h}$. Western blot analysis was used to detect TLR4 and MyD88 protein levels (Fig. 5A), and ELISA analysis was used to confirm the presence of TNF $\alpha$ and IL-1 $\beta$ proteins. The results indicated that levels of all four target proteins were increased significantly in the LPS stimulated cells, most notably in the $10 \mu \mathrm{g} / \mathrm{ml}$ LPS group (TLR4, all $\mathrm{P}<0.001 ; \mathrm{MyD} 88, \mathrm{P}=0.019, \mathrm{P}<0.001, \mathrm{P}<0.001$ and $\mathrm{P}<0.001$, respectively; TNF $\alpha$ and IL-1 $\beta$, all $\mathrm{P}<0.001$ ) (Fig. 5).

\section{Discussion}

The aims of the current study were to investigate whether TLR4 was expressed in IVD NP cells, and if so, whether its signaling was MyD88-dependent. Additionally, the response of NP cells to stimulation with a TLR4 ligand (LPS) was evaluated in vitro. To accomplish these goals, the presence of a functional TLR4 signal pathway in the IVD of rats was confirmed, and LPS was used to stimulate NP cells in order to assess the time phase-dependent association between LPS and the TLR4 signal pathway. The present results demonstrated that NP cells constitutively expressed TLR4 that could be activated by LPS at different time phase points. Subsequently, we used various concentrations of LPS to stimulate NP cells in order to ascertain the nature of the dose-dependent association between LPS and the TLR4 signal pathway. Indeed, TLR4 expression was modulated by stimulation with LPS in a dose-dependent manner via the MyD88-dependent signal pathway, resulting in upregulation of a coordinated set of proinflammatory mediators in vitro.

Currently, the treatment of symptomatic IVD degeneration consists of either conservative measures, such as the application of analgesics and physiotherapy or surgery in cases where conservative measures prove unhelpful (29). These approaches have not been shown to slow the degeneration process, and consequently, relapses or other adverse sequelae of discectomy, dynamic stabilization techniques, total disc replacement or fusion surgery may be expected (30-33). As IVD degeneration has a high prevalence and is associated with major socioeconomic costs, the current study sought to elucidate causative mechanisms underlying IVD degeneration in order to identify targets for its prevention and therapy.

Recent studies have partially elucidated the mechanisms of the LPS/TLR4 signaling pathway, and this understanding may be applied to model the regulation of additional TLR4 signaling pathways $(34,35)$. As improper regulation of LPS/TLR4 signaling has the potential to induce massive inflammation and cause acute sepsis or chronic inflammatory disorders, it is crucial to investigate this pathway further and evaluate novel targets to counteract these conditions $(36,37)$.

Consistent with the known response of TLR4 activation in the immune system, the present results indicated that the expression of TNF $\alpha$ and IL-1 $\beta$ in NP cells was significantly upregulated in response to various concentrations of LPS at various time points, confirming that TLR4 activation can trigger an inflammatory cascade in IVD NP cells. These findings demonstrated that LPS was capable of upregulating a coordinated set of inflammatory cytokines via the MyD88-dependent TLR4 signal pathway, and that the response to inflammatory stimulation was time phase- and dose-dependent.

In addition to the PAMPs, such as LPS from Gram-negative bacteria, a fusion protein from the respiratory syncytial virus, 
and the envelope protein from a mouse mammary tumor virus, TLR4 signaling may also be initiated by endogenous molecules that interact either directly or indirectly with TLR4, such as heat-shock proteins, hyaluronic acid and $\beta$-defensin 2 (34). LPS is among the most extensively studied immunostimulatory components of bacteria, and can induce systemic inflammation and sepsis if excessive signals occur (38). Furthermore, LPS is an important structural component of the outer membrane of Gram-negative bacteria, consisting of three parts; lipid A, core oligosaccharide and an $\mathrm{O}$ side chain. Lipid $\mathrm{A}$ is the main PAMP of LPS (34). Using the $\mathrm{C} 3 \mathrm{H} / \mathrm{HeJ}$ mouse strain, known to have a defective response to LPS, Beutler's group demonstrated that TLR4 was an important sensor for LPS (39). The active upregulation of TLR4 in IVD NP cells following LPS stimulation suggests that TLR4 may participate in these responses.

The ability of TLR4 activation by LPS to provoke the secretion of multiple cytokines may provide an opportunity to study broad aspects of the physiological inflammatory process in the IVD. Results from the current study suggest that in vivo inflammatory stimulation can induce degenerative changes in the IVD, without the use of physical destruction of disc integrity as an injury stimulus (6). Commonly used animal models of degeneration, where a stab or laceration lesion of the disc is performed, and reproduce morphological changes of IVD degeneration in general (40-43). These animal models have also been associated with transient increases in the expression or secretion of proinflammatory cytokines $(44,45)$, results that differ from what is observed in human degenerative disc diseases. Clinical disc degeneration in humans is associated with chronically elevated levels of multiple proinflammatory cytokines, indicative of the crucial roles that inflammatory mediators play in degenerative etiology. The findings of the current study indicate that altering the stimulus of degeneration, from physical disruption to an inflammatory stimulant, can also initiate a degenerative process in the IVD in vivo. This suggests that inflammatory insults alone may be able to initiate degeneration of the IVD.

The current study had several limitations. For example, LPS was the only agent used to interfere with the studied signal pathway. Additionally, we did not study any aspect of other TLR4 signal pathways, including the MyD88-independent pathway. In a planned study, we will interfere with different location points (e.g., MyD88 and TRAF6) along the TLR4 signal pathway using siRNA, and will also study changes to the ECM following activation of the TLR4 signal pathway.

In conclusion, the present findings confirm the activity of the MyD88-dependent TLR4 signal pathway in IVD NP cells in IVD degeneration, and that this signal pathway was stimulated by LPS in vitro. Activation of this pathway was time phase- and dose-dependent. When activated, this signal pathway led to the release of inflammatory factors that participated in IVD degeneration. Although these findings cannot be used directly to prevent and treat IVD degeneration, they suggest a potential therapeutic benefit of inhibition of the MyD88-dependent TLR4 signal pathway in degenerative disc disease. Therefore, the results of the current study provide a foundation for further investigations into therapeutic agents designed to prevent or treat IVD degeneration.

\section{Acknowledgements}

This study was supported by a grants from the Medical Scientific Research Foundation of Guangdong Province (grant no. B2013284), the Scientific Research Foundation of Guangzhou Medical University (grant no. 2012C61). and the Natural Science Foundation of Guangdong Province (grant no. 2016A030313607).

\section{References}

1. Deyo RA, Cherkin D, Conrad D and Volinn E: Cost, controversy, crisis: Low back pain and the health of the public. Annu Rev Public Health 12: 141-156, 1991.

2. Kabbara A and Hayek SM: Intradiscal electrothermal therapy (IDET) for the treatment of discogenic pain. Tech Reg Anesth Pain Manag 13: 102-108, 2009.

3. Cheung KM, Karppinen J, Chan D, Ho DW, Song YQ, Sham P, Cheah KS, Leong JC and Luk KD: Prevalence and pattern of lumbar magnetic resonance imaging changes in a population study of one thousand forty-three individuals. Spine (Phila Pa 1976) 34: 934-940, 2009.

4. Ireland D: Molecular mechanisms involved in intervertebral disc degeneration and potential new treatment strategies. Biosci Horiz 2: 83-89, 2009.

5. Maidhof R, Alipui DO, Rafiuddin A, Levine M, Grande DA and Chahine NO: Emerging trends in biological therapy for intervertebral disc degeneration. Discov Med 14: 401-411, 2012.

6. Rajan NE, Bloom O, Maidhof R, Stetson N, Sherry B, Levine M and Chahine NO: Toll-like receptor 4 (TLR4) expression and stimulation in a model of intervertebral disc inflammation and degeneration. Spine (Phila Pa 1976) 38: 1343-1351, 2013.

7. Antoniou J, Steffen T and Nelson F, Winterbottom N, Hollander AP, Poole RA, Aebi M and Alini M: The human lumbar intervertebral disc: Evidence for changes in the biosynthesis and denaturation of the extracellular matrix with growth, maturation, ageing, and degeneration. J Clin Invest 98: 996-1003, 1996.

8. Roughley PJ, Alini M and Antoniou J: The role of proteoglycans in aging, degeneration and repair of the intervertebral disc. Biochem Soc Trans 30: 869-874, 2002.

9. Le Maitre CL, Freemont AJ and Hoyland JA: Localization of degradative enzymes and their inhibitors in the degenerate human intervertebral disc. J Pathol 204: 47-54, 2004.

10. Pockert AJ, Richardson SM and Le Maitre CL, Lyon M, Deakin JA, Buttle DJ, Freemont AJ and Hoyland JA: Modified expression of the ADAMTS enzymes and tissue inhibitor of metalloproteinases 3 during human intervertebral disc degeneration. Arthritis Rheum 60: 482-491, 2009.

11. Goldring MB: The role of the chondrocyte in osteoarthritis. Arthritis Rheum 43: 1916-1926, 2000.

12. Lee S, Moon CS and Sul D, Lee J, Bae M, Hong Y, Lee M, Choi S, Derby R, Kim BJ, et al: Comparison of growth factor and cytokine expression in patients with degenerated disc disease and herniated nucleus pulposus. Clin Biochem 42: 1504-1511, 2009.

13. Masuda K, Imai Y and Okuma M, Muehleman C, Nakagawa K, Akeda K, Thonar E, Andersson G, An HS: Osteogenic protein-1 injection into a degenerated disc induces the restoration of disc height and structural changes in the rabbit anular puncture model. Spine 31: 742-754, 2006.

14. Ellman MB, Kim JS and An HS, Chen D, KC R, An J, Dittakavi T, van Wijnen AJ, Cs-Szabo G, Li X, et al: Toll-like receptor adaptor signaling molecule MyD88 on intervertebral disk homeostasis: in vitro, ex vivo studies. Gene 505: 283-290, 2012.

15. Weiler C, Nerlich AG, Bachmeier BE and Boos N: Expression and distribution of tumor necrosis factor alpha in human lumbar intervertebral discs: A study in surgical specimen and autopsy controls. Spine (Phila Pa 1976) 30: 44-53; discussion 54, 2005.

16. Le Maitre CL, Hoyland JA and Freemont AJ: Catabolic cytokine expression in degenerate and herniated human intervertebral discs: IL-1beta and TNFalpha expression profile. Arthritis Res Ther 9: R77, 2007.

17. Tukhvatulin AI, Logunov DY, Shcherbinin DN, Shmarov MM, Naroditsky BS, Gudkov AV and Gintsburg AL: Toll-like receptors and their adapter molecules. Biochemistry (Mosc) 75: 1098-1114, 2010. 
18. Janeway CJ and Medzhitov R: Innate immune recognition. Annu Rev Immunol 20: 197-216, 2002.

19. Akira S, Uematsu S and Takeuchi O: Pathogen recognition and innate immunity. Cell 124: 783-801, 2006.

20. Lee HK and Iwasaki A: Innate control of adaptive immunity: Dendritic cells and beyond. Semin Immunol 19: 48-55, 2007.

21. Takeda K, Kaisho T and Akira S: Toll-like receptors. Annu Rev Immunol 21: 335-376, 2003.

22. Beutler B: Inferences, questions and possibilities in Toll-like receptor signalling. Nature 430: 257-263, 2004.

23. Youn HS, Lee JY, Fitzgerald KA, Young HA, Akira S and Hwang DH: Specific inhibition of MyD88-independent signaling pathways of TLR3 and TLR4 by resveratrol: Molecular targets are TBK1 and RIP1 in TRIF complex. J Immunol 175: 3339-3346, 2005.

24. Akira S, Takeda K and Kaisho T: Toll-like receptors: Critical proteins linking innate and acquired immunity. Nat Immunol 2: 675-680, 2001

25. Hiyama A, Sakai D, Risbud MV, Tanaka M, Arai F, Abe K and Mochida J: Enhancement of intervertebral disc cell senescence by $\mathrm{WNT} / \beta$-catenin signaling-induced matrix metalloproteinase expression. Arthritis Rheum 62: 3036-3047, 2010.

26. Wang F, Wu XT, Zhuang SY, Wang YT, Hong X, Zhu L and Bao JP: Ex vivo observation of human nucleus pulposus chondrocytes isolated from degenerated intervertebral discs. Asian Spine J 5: 73-81, 2011

27. Mao M, Lei H, Liu Q, Chen Y, Zhao L, Li Q, Luo S, Zuo Z, He Q, Huang W, et al: Effects of miR-33a-5P on ABCA1/G1-mediated cholesterol efflux under inflammatory stress in THP-1 macrophages. PLoS One 9: e109722, 2014.

28. Livak KJ and Schmittgen TD: Analysis of relative gene expression data using real-time quantitative PCR and the 2(-Delta Delta C(T)) Method. Methods 25: 402-408, 2001.

29. McGirt MJ, Ambrossi GL, Datoo G, Sciubba DM, Witham TF, Wolinsky JP, Gokaslan ZL and Bydon A: Recurrent disc herniation and long-term back pain after primary lumbar discectomy: Review of outcomes reported for limited versus aggressive disc removal. Neurosurgery 64: 338-344; discussion 344-345, 2009.

30. Glassman SD, Carreon LY, Djurasovic M, Dimar JR, Johnson JR, Puno RM and Campbell MJ: Lumbar fusion outcomes stratified by specific diagnostic indication. Spine J 9: 13-21, 2009.

31. Mirza SK and Deyo RA: Systematic review of randomized trials comparing lumbar fusion surgery to nonoperative care for treatment of chronic back pain. Spine 32: 816-823, 2007.
32. Galbusera F, Bellini CM and Zweig T, Ferguson S, Raimondi MT, Lamartina C, Brayda-Bruno M, Fornari M: Design concepts in lumbar total disc arthroplasty. Eur Spine J 17: 1635-1650, 2008.

33. Bothmann M, Kast E, Boldt GJ and Oberle J: Dynesys fixation for lumbar spine degeneration. Neurosurg Rev 31: 189-196, 2008.

34. Lu YC, Yeh WC and Ohashi PS: LPS/TLR4 signal transduction pathway. Cytokine 42: 145-151, 2008.

35. Barton GM and Medzhitov R: Toll-like receptor signaling pathways. Science 300: 1524-1525, 2003.

36. O'Neill LA: Targeting signal transduction as a strategy to treat inflammatory diseases. Nat Rev Drug Discov 5: 549-563, 2006.

37. Kanzler H, Barrat FJ, Hessel EM and Coffman RL: Therapeutic targeting of innate immunity with Toll-like receptor agonists and antagonists. Nat Med 13: 552-559, 2007.

38. Netea MG, van Deuren M, Kullberg BJ, Cavaillon JM and Van der Meer JW: Does the shape of lipid A determine the interaction of LPS with Toll-like receptors? Trends Immunol 23: 135-139, 2002.

39. Beutler B: Tlr4: Central component of the sole mammalian LPS sensor. Curr Opin Immunol 12: 20-26, 2000.

40. Masuda K, Aota Y, Muehleman C, Imai Y, Okuma M, Thonar EJ, Andersson GB and An HS: A novel rabbit model of mild, reproducible disc degeneration by an anulus needle puncture: Correlation between the degree of disc injury and radiological and histological appearances of disc degeneration. Spine (Phila Pa 1976) 30: 5-14, 2005.

41. Sobajima S, Kompel JF, Kim JS, Wallach CJ, Robertson DD, Vogt MT, Kang JD and Gilbertson LG: A slowly progressive and reproducible animal model of intervertebral disc degeneration characterized by MRI, X-ray and histology. Spine (Phila Pa 1976) 30: 15-24, 2005.

42. Kim KS, Yoon ST, Li J, Park JS and Hutton WC: Disc degeneration in the rabbit: A biochemical and radiological comparison between four disc injury models. Spine (Phila Pa 1976) 30: 33-37, 2005.

43. Rousseau MA, Ulrich JA, Bass EC, Rodriguez AG, Liu JJ and Lotz JC: Stab incision for inducing intervertebral disc degeneration in the rat. Spine (Phila Pa 1976) 32: 17-24, 2007.

44. Sobajima S, Shimer AL, Chadderdon RC, Kompel JF, Kim JS, Gilbertson LG and Kang JD: Quantitative analysis of gene expression in a rabbit model of intervertebral disc degeneration by real-time polymerase chain reaction. Spine J 5: 14-23, 2005.

45. Ulrich JA, Liebenberg EC, Thuillier DU and Lotz JC: ISSLS prize winner: Repeated disc injury causes persistent inflammation. Spine (Phila Pa 1976) 32: 2812-2819, 2007. 